\title{
A Carrot and Stick Approach to Agenda-Setting*
}

\author{
Matthias Dahm ${ }^{\dagger} \quad$ Amihai Glazer ${ }^{\ddagger}$
}

August 19, 2015

\begin{abstract}
This paper models a legislature in which the same agenda setter serves for two periods, showing how he can exploit a legislature (completely) in the first period by promising future benefits to legislators who support him. In equilibrium, a large majority of legislators vote for the firstperiod proposal because they thereby maintain the chance of belonging to the minimum winning coalition in the future. Legislators may therefore approve policies by large majorities, or even unanimously, that benefit few, or even none, of them. The results are robust. But institutional arrangements (such as entitlements) can reduce the agenda setter's power by reducing his discretion to reward and punish legislators, and rules (such as sequential voting) can increase a legislator's ability to resist exploitation.

Keywords: Legislative bargaining, distributive politics, agenda setting JEL: C72, D72, D78
\end{abstract}

*We thank the editor and referees of the Journal, seminar audiences at the 2014 European Public Choice Society Meetings, the Tinbergen Institute in Rotterdam, the University of Karlsruhe, University of Manchester and the Universitat Rovira i Virgili for helpful discussions and suggestions. The usual disclaimer applies. Dahm acknowledges the support of the Government of Catalonia, and of the Government of Spain under projects SEJ2007-67580-C02-01 and ECO2010-19733.

†School of Economics, University of Nottingham, University Park, Nottingham NG7 2RD, United Kingdom. matthias.dahm@nottingham.ac.uk

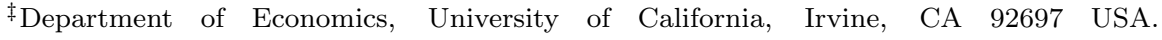
aglazer@uci.edu 


\section{Introduction}

Much legislation is usefully viewed as imposing a tax on all legislators (or their constituents), and distributing the benefits among only some individuals or groups. It may therefore appear that proposed legislation can gain majority support only if in a majority of districts the amounts distributed exceed the taxes collected. The existence of large majorities thus suggests wide benefits from a policy. Nevertheless, redistributive legislation often gains strong political support though benefits are concentrated among few districts (as with farm bills). ${ }^{1}$ In these cases suspicion falls on special interests with much influence.

Our explanation differs, allowing current policy proposals and voting outcomes to depend not only on current benefits, but also on past decisions and on expectations of future behavior. These implicit connections between policies were well captured by a study of the Connecticut legislature (Barber 1996) that reports

But for a considerable number, the relevant patronage is not that which can be offered here and now, but, in effect, all the patronage which the leaders are expected to control in the future. For these members the important thing is to build a favorable record of party service, so that when and if some opportunity is presented, perhaps years hence, they will be among the eligibles... Party allegiance is motivated in part by vague hopes that sometime in the future, should the member want help of some unspecified kind - a job, an administrative decision, a local bill passed - the leadership would remember his yeoman service in the party ranks. As one legislator said, "It isn't what you've been promised, it's what you hope for that helps, that will swing a person into line."

The analysis below formalizes and extends this idea, focusing on an agenda setter who issues promises and threats, showing how he can induce a majority of

\footnotetext{
${ }^{1}$ Agricultural policy in the U.S. is periodically renewed. Consider the Food, Conservation, and Energy Act of 2008. It passed in the House (Vote \#353) by 306/110 and in the Senate (Vote \#144) by 77/15. Moreover, both the House and the Senate overrode a veto by the President with a 2/3 majority. Data on commodity subsidies from 1995-2010 for 400 congressional districts shows that the 24 districts ( $6 \%$ of all districts listed) that received the largest subsidies obtained $52.8 \%$ of the total of $\$ 167.3$ billion.
} 
legislators to vote for a policy that directly benefits few, or even none, of them: he threatens legislators voting against him in one period that he will exclude them from the winning coalition in a following period. Of course, an agenda setter cannot always exploit the legislature; for example, he may be unable to forbid amendments to a policy he proposes. Rather, one contribution of our analysis is to point to conditions that allow for exploitation, and conditions or institutional arrangements that limit it.

A classic example of a legislative leader who long controlled the agenda and used this power, among other powers, to control policy is Joseph Cannon, Speaker of the U.S. House of Representatives from 1903 to 1911, and called at the time the "Tyrant from Illinois." He was reported to punish disloyal members by refusing to schedule their favored legislation, and declining to recognize them to offer amendments or private bills. When chairing the House Rules Committee, he limited amendments that could be made on the floor of the House. Nevertheless, he did not punish all opponents or reward all supporters. Our model can explain how an agenda setter can wield great power even when rewards and punishments are rare or small.

Our analysis has more than historical interest. Though currently the Speaker has less power than Cannon enjoyed, congressional committees have agendasetting powers, particularly when the vote on the floor of the House of Representatives is made under the closed rule. ${ }^{2}$ Thus, congressmen with some agendasetting power enjoy greater pork-barrel spending in their districts. Such congressmen include party leaders (Balla et al. 2002; Hird 1991), committee chairs (Ferejohn 1974), and members of prestige committees, especially the Appropriations Committee (de Figueiredo and Silverman 2006). Members of Congress with proposal power - those sitting on the Transportation Committee - get more spending on transportation projects in their districts than do other congressmen (Knight 2005). ${ }^{3}$

A study of earmarks in senatorial bills finds that the number of earmarks

\footnotetext{
${ }^{2}$ Price (2006) reports that the incidence of completely closed rules that preclude the offering of any amendments whatsoever, including the traditional minority substitute, was $28 \%$ in the 108th Congress (2003-2005). Doran (2010) reports that the closed rule is now used for half of the controversial House floor agenda.

${ }^{3}$ Because, however, different committees may have agenda-setting powers over different policy areas, the benefits members of any one committee can gain may be smaller than the benefits gained by an agenda setter with control over all policy proposals, which we consider.
} 
Senate majority leader Harry Reid received was more than one standard deviation above the mean number of earmarks for the Senate (Engstrom and Vanberg 2010). In both the Senate and the House, members of the Appropriations Committees received larger earmarks. In the House, party leaders received more earmarks (Lazarus and Steigerwalt 2009). Similarly, Hardin (1958) argues that farm policy is inefficient, but nevertheless supported in the U.S. Congress, because committee chairmen with agenda power come from farm districts.

In different settings different people can set the agenda. Under fast-track legislation in the U.S., the president proposes a treaty that Congress can either accept or reject, but not amend. In the European Union, the Commission has significant agenda-setting power: in some policy domains, only the Commission can propose a policy, and the power of the Council and the Parliament to amend the proposal may be restricted (as by super-majority requirements) depending on the legislative procedure used. Many parliamentary democracies allow the government to propose a policy as a confidence vote, which the legislature can adopt or reject, but not amend. In Germany, Finland, France, Italy, Portugal and Spain, the constitution authorizes the government to make policies questions of confidence. By convention, the government can make the vote on a specific policy a question of confidence in Australia, Canada, the Netherlands, New Zealand, Norway, and the United Kingdom. Other parliaments permit votes of confidence. For example, in 1995 members of the Italian Lower House proposed more than 150 amendments to a budget introduced by the Prime Minister. The Prime Minister eventually invoked a confidence vote procedure on his budget package, which the legislature passed without the amendments. ${ }^{4}$

The agenda setter could more generally be the bureaucracy, as in the seminal work by Romer and Rosenthal (1978). But their model underestimates the agenda setter's power, because it assumes voters must be indifferent between the proposal and the status quo, without looking at the bureaucracy's ability to punish opponents. Niskanen (1971) similarly assumes that the executive branch's power is limited to making take-it-or-leave-it offers. Thus, they do not consider the possibility that all voters vote for a policy in some period which hurts them all. We do.

Our model has the agenda setter credibly punish legislators. Such threats are observed. When Senator James Buckley tried to delete forty-four public works

\footnotetext{
${ }^{4}$ This discussion of confidence votes is based on Huber (1996).
} 
projects at the committee stage in the Senate, the members voted down all his amendments, but cut out projects in his home state (as reported by Epple and Riordan 1987). Senator William Proxmire was similarly punished for supporting proposals to cut appropriations for the Department of the Interior - a HouseSenate Conference Committee deleted the senator's favored project from the Interior appropriations bill (see Ferejohn 1974, p. 114).

The problem we address differs from logrolling. Logrolling has a majority of legislators support a package of policies which benefit each member of the majority, though any one component benefits only one legislator. We consider a policy proposal that hurts all legislators.

Our model has several important features. Some of these are found in other work, but no work has all of them. First, in equilibrium, in period 1 all legislators vote for a policy that gives each of them negative utility, whereas the outside option gives each zero utility. The result is therefore much stronger than merely saying that a supermajority support redistribution to a minority. Second, the result is reasonably robust, holding when voting is by secret ballot, when the time horizon is finite, when the agenda setter can be replaced, and when legislators can be replaced. Third, the result is time consistent- the agenda setter need not commit to an action in period 2 that he would prefer to avoid. Fourth, the result holds even if a legislator's vote is decisive. It is not merely that a legislator votes for the bad policy because the outcome would be the same if he voted against the bad policy; instead each legislator strictly prefers to vote for the bad policy. Fifth, in contrast to results that appear because the Folk Theorem applies in a game with an infinite horizon, our results apply in a game with two periods. In contrast to bargaining models which show that any distribution of a surplus can be sustained in equilibrium, we consider a negative-sum game.

The paper is organized as follows. The next section reviews related literature. Sections 3 and 4 formalize a benchmark model of agenda setting in which the proposer controls the agenda: he is the unique proposer, amendments are not possible, and he is certain to stay in power. Sections 5 and 6 consider different institutional arrangements, investigating whether they can balance power between the agenda setter and the legislature. This highlights the importance of, for example, the cohesion of the legislature to sustain tacit collusion against the agenda setter, or the separation of budgetary powers and entitlements. It 
also yields the surprising finding that a secret ballot alone might not be enough. The last section contains concluding remarks.

\section{Literature}

\subsection{Agenda setting}

Studies of agenda setting usually need to refine equilibrium predictions by considering 'simple' strategies which only depend on current payoff-relevant variables. This constraint precludes investigating the power of promises and threats, on which we focus.

Important early contributions include Romer and Rosenthal (1978), Baron and Ferejohn (1989), Baron (1989), and Harrington (1990). They assume that in each period any legislator can be chosen to make a proposal. In proposing and voting on policies, a legislator must thus compare the benefits from the proposal to the status quo, and to a future proposal in which the legislator may be excluded from the minimum winning coalition. The sequence of proposal makers gives an early proposer power to gain more benefits to himself than other members of the majority gain. In important extensions, Ali, Bernheim and Fan (2014) show that even if legislators are uncertain about who will be the agenda setter in following periods, and even if it is known that the current agenda setter will be replaced, the first proposer can extract the entire surplus for himself in every subgame perfect equilibrium of a finite horizon game. The essential intuition is that the inability of future agenda setters to commit to who will get benefits gives a current agenda setter much power. Our result is even stronger: in some periods each member of the legislature is made strictly worse off by the policy they unanimously pass. Whereas other papers look at the division of a fixed prize, we look at a tax-cum-spending policy which allows for negative utility for legislators supporting the policy.

Some work considers endogenously evolving default policies, and yield exploitation results closer to ours. How legislators can obtain local benefits is discussed by Bernheim, Rangel, and Rayo (2006), who consider the default policy changing from period to period, a single policy implemented in the final period, and the agenda setter in each period offering a policy which depends on the policy that was most recently adopted. The authors show that a majority 
may support a pork-barrel policy which hurts almost every legislator. Anesi and Seidmann (2013) show in a related model that even a non-proposer may obtain all of the surplus. Other papers consider a sequence of policies. Kalandrakis (2004) considers a continuous policy space, and Diermeier and Fong (2011) consider a discrete policy in modeling a legislature in which a player is selected at random to make a proposal in each round. The proposal is pitted against the status quo, with the winning alternative becoming the status quo in the next round of bargaining. The equilibrium has the proposer eventually extract all benefits for himself in all periods. If, however, a policy can be reconsidered, then legislators have an incentive to protect each other and limit the power of the agenda setter.

\subsection{Size of winning coalitions}

The literature looks at two extreme forms of winning coalitions. One approach, introduced by Riker (1962), predicts the existence of minimum winning coalitions - why should the agenda setter, or for that matter any member of the majority, offer anything to the minority. The models of agenda setting described above also predict minimum winning coalitions.

The other extreme examines conditions under which policies will be passed by very large majorities, with benefits going to almost all legislators. Legislators operating under a "veil of ignorance" (they do not know which coalitions will form in the future) will adopt a norm of universalism that calls for all legislators to benefit from pork barrel projects (Weingast 1979, Shepsle and Weingast 1981, and Grofman 1984). Costs of drafting policy can affect the policies a legislator proposes, by inducing him to propose policies which are supported by a large majority of legislators (Glazer and McMillan 1992), or by proposing policies which other legislators would later not want to amend (Glazer and McMillan 1990). An extension of the Baron-Ferejohn model to consider incomplete information is given by Tsai and Yang (2010), showing that oversized coalitions may appear. Relatedly, the Baron-Ferejohn model with sequential voting is examined by Norman (2002), who shows that any allocation of benefits can constitute an equilibrium. In a model of endogenously evolving default policies, Anesi and Seidmann (2015) show that oversized coalitions can be an equilibrium feature. But in these models no one suffers from a policy; in our model all legislators prefer that the agenda setter's proposal be rejected. 
Work on vote buying shows that the equilibrium may have supermajorities. In Groseclose and Snyder (1996) and Banks (2000) the special interest which moves first buys a supermajority of votes to make vote buying prohibitively expensive for the special interest which moves second. Zapal (2013) finds that the equilibrium can have supermajorities in a model with a single vote buyer who can give favors to legislators, but is uncertain how legislators will vote. Felgenhauer and Grüner (2008) also consider a single vote buyer and uncertainty in voting, studying information aggregation under secret and non-secret ballots.

\subsection{Punishing opponents and rewarding supporters}

The idea that a political leader rewards supporters and punishes opponents is of course not novel. The Introduction mentioned how Joseph Cannon, as Speaker of the House of Representatives, used such tools. Papers discussed above had an agenda setter ignore how legislators voted in the past in deciding what proposal to make. When such history is considered, punishment strategies can arise: an agenda setter who can exclude from the majority coalition legislators who had voted against him can capture a large share of the budget (Baron and Ferejohn 1989, Cotton 2010).

Dal Bó (2007) analyzes how an outside party can use bribes that are conditional on the realized voting profile to influence committee decisions. He shows that a special interest group can generate unanimous approval, although in equilibrium payments are very small. His key insight is that "pivotal bribes," in which a legislator is paid if and only if he casts a decisive vote for the policy, render the voting game a multilateral prisoners' dilemma. ${ }^{5}$ Though the analysis below relies on these insights, the influence mechanism differs from his-we allow compensations to be conditioned only on a legislator's vote, which under his model does not allow for costless capture. Dal Bó assumes the special interest commits to payments it will make after votes are realized, whereas in our setting compensations are costless for the agenda setter and thus credible. Whereas Dal Bó allows for cash payments, in much of our analysis the agenda setter is restricted to excluding or including legislators in a minimum winning coalition in a future period. That limitation may appear to limit greatly an

\footnotetext{
${ }^{5}$ The model is extended by Console-Battilana and Shepsle (2009), who consider payments that either the president or lobbying groups can make to induce legislators to confirm the appointment of a supreme court justice.
} 
agenda-setter's power in earlier periods; we show when it does not. One way of noting that our approach differs fundamentally is that our mechanism will operate only if legislators vote in sequence on at least two policies; results in Dal Bó appear even if legislators vote only once.

An incumbent, even one who pursues policies that most oppose, can stay in power if members of the incumbent's winning coalition are more likely to become members of the winning coalition in the future than are members of the challenger's coalition (Bueno de Mesquita et al. 2002). The PRI party in Mexico maintained power by threatening districts that did not support it that they will be denied private benefits from the central government which the PRI controlled (see Diaz-Cayeros, Magaloni, and Weingast 2003). Relatedly, a group's fear of later falling under an inefficient and venal ruler who favors another group can suffice to discipline supporters (Padró i Miquel 2007). And in discussing governance, Dixit (2009) argues that private order can be sustained by the threat of expulsion. Punishment strategies can be more effective if the principal has some discretion, as shown below in considering entitlements. The importance of discretion in allowing punishment is analyzed by Bernheim and Whinston (1998), who show that when some outcomes cannot be verified, leaving the obligations of contracting parties vague or unspecified can enhance efficiency.

The power of an agenda setter to punish opponents is considered by Epple and Riordan (1987), who examine repeated interactions, with different individuals having the right to propose policies in different periods, showing that a wide range of allocations can be sustained as equilibria by the threat of political banishment. Like them, we suppose that the punishment for defection is exclusion, which in equilibrium is not invoked. Their result on plutocracy resembles our result about the agenda setter exploiting others. But whereas they consider punishment by multiple legislators, we consider punishment by the agenda setter. They consider an infinite horizon whereas we have a finite horizon. And whereas they consider complicated strategies, ours is simple. Moreover, we extend the analysis in several ways, including sequential voting, tacit collusion, and the agenda setter's decision of whether to privilege the status quo. 


\section{Assumptions}

We start the analysis with a simple benchmark model. Most assumptions are generalized in later sections.

There are four players. One person, say the President, or the Speaker of the House, or the majority of a legislative committee, is the agenda setter in each of two periods. ${ }^{6} \mathrm{He}$, and only he, can propose a policy. The legislature consists of three members. The agenda setter's proposal is adopted if a majority of legislators vote for it (or vote yes). (We later extend the analysis to consider super-majority and unanimity rules.) Votes are public and simultaneous. The agenda setter does not vote. The assumptions are consistent with an interpretation of the agenda setter as the U.S. President who is not a member of Congress, or the European Commission which submits a proposal to the European Parliament and the Council of Ministers. ${ }^{7}$

In each of two periods the agenda setter proposes a policy that costs a dollar, and that divides that dollar (perhaps unequally) among the three legislators and himself. If the policy is adopted, a tax of $\$ 1 / 3$ is imposed on each of the three legislators. If the policy is rejected, no tax is paid and no benefits are distributed. $^{8}$

In period 1, the agenda setter must treat each legislator equally; he cannot target a subset of legislators or make the payments conditional on votes. One justification is that, as we show in the context of Proposition 1 below, sometimes the agenda setter can obtain the whole surplus in period 1 and thus prefers not to build a minimum winning coalition in both periods. In this case our

\footnotetext{
${ }^{6}$ Consistent with our assumptions, Primo (2002) notes that most political bargaining in the U.S. Congress has only one actor make a formal proposal. Also, consistent with our assumption that the agenda setter remains in power, Cotton (2010) reports that agendasetting authority in the U.S. Congress rarely changes hands. Since the first U.S. Congress in 1789, for example, there have been only 59 changes in the Speaker of the House, of which no more than 24 can be attributed to the speaker losing support amongst his party. Diermeier and Fong (2011) give further examples of institutions, among them central banks, in which an agenda setter persistently controls proposals.

${ }^{7}$ Were the agenda setter a voting member of the legislature, he would find it easier to win approval for his proposal - he would need the support of fewer legislators (just one other legislator is needed as opposed to two in our setting, in which the agenda setter has no vote).

8 An alternative version of our model considers a legislature composed of three legislators, who each pay taxes and vote, with one of them the agenda setter. This would not change our qualitative results; details are available upon request.
} 
assumption is innocuous and simplifies the exposition. Second, as discussed in the context of Proposition 2 below, sometimes the agenda setter would do better without this restriction. In this case our assumption makes it more difficult to explain support for the proposal made in period 1, and so makes our results more striking. ${ }^{9}$ In period 2 the agenda setter can again propose to impose a tax of $\$ 1 / 3$ on each legislator, and to distribute the $\$ 1$ thus raised between himself and legislators in any way he wants.

The agenda setter maximizes his benefits, subject to the constraint that his proposal is approved only if a majority of legislators vote for it. His possibilities in period 1 are as follows. He proposes to impose a tax of $1 / 3$ on each legislator, to give $s \leq 1 / 3$ to each legislator, and to give $1-3 s$ to himself. Optimization by the agenda setter requires minimizing the side payments $s$; we will investigate how $s$ depends on the institutional constraints.

Each legislator cares only about the net benefits he gets. He votes yes if the present discounted value of doing so exceeds the present discounted value of voting no.

We look at subgame perfect, or time-consistent, solutions. Collusion in a two-period model is therefore impossible. The intertemporal discount factor is $\delta>0$. The time line is as follows

1. The agenda setter proposes a policy, which describes benefits to himself and to each legislator, and a tax divided equally among the legislators to finance the benefits.

2. The agenda setter's proposal is adopted if a majority of legislators vote yes

3. Payoffs are realized

4. The agenda setter again proposes a policy, which describes benefits to himself and to each legislator, and a tax divided equally among the legislators to finance the benefits.

5. The agenda setter's proposal is adopted if a majority of legislators vote yes

\footnotetext{
${ }^{9}$ For example, in the context of Proposition 2 below, without this restriction the agenda setter could secure approval of his proposal in period 1 at lower cost to himself by offering a share of the dollar to only two legislators.
} 
6. Payoffs are realized

\section{Benchmark result}

Let the agenda setter use the following strategy. In period 1 he threatens that any legislator who votes no will be politically banished, in the sense that his chance of becoming a member of a future minimum winning coalition is smaller than that of a legislator who voted yes. In period 2 the agenda setter proposes to split a dollar equally with the members of a minimum winning coalition. Any legislator who supported him in period 1 has an equal chance of belonging to the minimum winning coalition in period $2 .{ }^{10}$ If a minimum winning coalition requires more members than the number of legislators who voted yes in period 1 , then the remaining members are chosen with equal probability among the legislators who voted no in period 1. Call this the exclusion strategy.

Consider period 2. In that period the agenda setter proposes to give $1 / 3$ to each of the two legislators, 0 to the third legislator, $1 / 3$ to himself, and a $\operatorname{tax}$ of $1 / 3$ on each of the legislators. No member of the minimum winning coalition (the two legislators offered $1 / 3$ each) gains by rejecting the proposal, and the proposal is supported by a majority. An equilibrium does exist with all legislators voting no in period 2-no one legislator's vote can then change the outcome, and thus no legislator has an incentive to deviate. This equilibrium, however, is not robust to a trembling hand. ${ }^{11}$ We shall refer to equilibria in which this refinement applies as robust equilibria.

Turn now to period 1. Given that all legislators face the same situation, we focus on a symmetric equilibrium in pure voting strategies. Consider a given legislator who expects all other legislators to vote yes. Notice that a single vote does not change the outcome of the collective decision which approves the proposal. A legislator who votes yes has a $2 / 3$ chance of belonging to the

\footnotetext{
${ }^{10}$ Norman (2002) makes a similar assumption. We assume equal chances for simplicity; the results hold under weaker assumptions (see the discussion after Proposition 1).

${ }^{11}$ Assume that the agenda setter plays an exclusion strategy in which he offers in period 2 a very small benefit $b>0$ to members of the winning coalition. If with some small probability one of the legislators will vote for the agenda setter's proposal in period 2, then a legislator favored by that proposal strictly prefers to vote yes. The following uses this refinement, supposing that the period 2 proposal is accepted. A technical issue concerns the existence of the optimal amount to offer. That may be solved by making the realistic assumption that a smallest monetary unit exists.
} 
minimum winning coalition in period 2 , in which case his benefit is $1 / 3$. So, considering the taxes he will pay, his expected net benefit when he votes yes is $-1 / 3(1+\delta)+s+\delta 2 / 9$. A legislator who votes no will be excluded from the minimum winning coalition in period 2 ; his payoff is only $-1 / 3(1+\delta)+s$. Thus, for any $s$ a legislator strictly prefers to vote yes in period 1. It is an equilibrium for each legislator to vote yes. ${ }^{12}$

The agenda setter maximizes his surplus by setting $s=0$; because he obtains the largest possible surplus, clearly he has no better strategy. In period 1 he obtains the whole surplus, whereas in period 2 his surplus is maximized subject to the constraint that the proposal be accepted. Further reducing the share given members of the minimum winning coalition in period 2 would yield strictly negative benefits to each member, causing them to reject the proposal. The above strategies thus constitute a subgame perfect equilibrium.

Moreover, a Nash equilibrium in pure voting strategies cannot have all legislators in period 1 vote no. Assume they do. Again a single vote does not change the outcome of the collective decision which rejects the proposal. But a legislator who votes yes in period 1 will belong to the minimum winning coalition in period 2. Hence, a legislator who votes yes has zero payoff in period 2. Voting no reduces the chance of belonging to the minimum winning coalition in period 2 , so that total payoffs are $0+\delta(2 / 9-1 / 3)<0$. The difference is $\delta / 9>0$, which represents the benefit from ensuring membership in the minimum winning coalition in period 2. Thus, a legislator strictly prefers to vote yes in period 1; it is not an equilibrium for all legislators to vote no.

We summarize with

Proposition 1 A symmetric subgame perfect equilibrium in pure voting strategies exists in which

- the agenda setter plays the exclusion strategy with $s=0$ and

\footnotetext{
${ }^{12}$ We do not have data on whether overwhelming majorities support policies which benefit the agenda setter. But data do show that much legislation is passed with very large majorities. King and Zeckhauser (2003) report that in the 1997-98 session of the U.S. House of Representatives, 324 non-procedural roll-call votes, which constitute $42 \%$ of the total, passed with more than 300 votes in a chamber with 435 members. The results are not atypical. Data on the U.S. House of Representatives over the years 1873-1998 show that overwhelming majorities (with ninety percent of those voting on the same side) appear on over forty percent of the roll-call votes in several sessions, and occur on over 25 percent of the roll-call votes in about half of the congressional sessions (Gaines and Sala 2000).
} 
- in period 1 the legislature unanimously approves the agenda setter's proposal; in period 2 a minimum winning coalition approves the proposal the agenda setter makes in that period.

Moreover, for any exclusion strategy with $s \geq 0$, it is not a robust equilibrium for legislators to vote unanimously against the agenda setter's proposal in period 1 .

The qualitative results are not a knife-edge; they do not require that in period 2 the agenda setter must be indifferent about the composition of his coalition. First, for emotional reasons, in period 2 the agenda setter may prefer to exclude someone who had voted against him in period 1. Second, the motivation for the agenda setter to randomize among the legislators who voted no in period 1 is analogous to the standard argument for mixed-strategies: mixed strategies produce unpredictable choices that cannot be exploited by the members of the legislature. Third, all that is needed for the results is that a legislator who voted yes in period 1 will more likely belong to the winning coalition in period 2 than a legislator who voted no. The agenda setter's choice would be equally unpredictable were it common knowledge that if all legislators vote yes in period 1, legislators 1, 2 and 3 will be included in the minimum winning coalition in period 2 with probability $1 / 3,2 / 3$ and 1 , respectively. ${ }^{13}$

The behavior of legislators could make voters in any one legislative district dislike what the legislature does (adopt policies that hurt all districts), but like what the legislator from their own district does (minimize losses to the district, given how other legislators vote). In the United States, that would lead voters to hate Congress but to like their own congressman, a pattern consistent with polling results. For example, a Gallup poll in 2013 finds the common pattern that "...when thinking about Congress as a whole, Americans are nearly as sour as they have ever been, but when they think just about their own representative, they feel much better about the job that person is doing." 14

Proposition 1 imposes two restrictions that when relaxed might lead to further equilibria: voting strategies in period 1 are symmetric and pure. The next

\footnotetext{
13 We could derive asymmetric probabilities analogously to recent micro-foundations for contest success functions by Corchón and Dahm (2010 and 2011). One possibility assumes that the agenda setter is not indifferent about the identity of the legislators included in the period 2 minimum winning coalition, and legislators are uncertain about the agenda setter's preferences. Details are available upon request.

${ }^{14}$ www.gallup.com/poll/162362/americans-down-congress-own-representative.aspx.
} 
subsection explores the existence of asymmetric equilibria. Appendix A.1 shows that even allowing for mixed voting strategies, when the discount factor is sufficiently large (roughly greater than 0.6), the equilibrium in Proposition 1 is the unique robust symmetric equilibrium . The reason is that for high discount factors, the agenda setter can offer sufficient side payments so that an equilibrium with mixed strategies does not exist. For low discount factors, however, an equilibrium with mixed strategies does exist. But it is not surprising that the agenda setter loses power as the future becomes less important, because his power is based on his ability to allocate future benefits. Moreover, even with mixed strategies the legislature approves the proposal in period 1 with positive probability, implying that the agenda setter can sometimes exploit the legislature.

\subsection{Eliminating asymmetric equilibria with side payments}

Suppose legislators respond to the exclusion strategy (when $s=0$ ) by playing asymmetric pure voting strategies in period 1, with two legislators voting against and one legislator voting for the agenda setter's proposal. ${ }^{15}$ Then the agenda setter's payoffs in period 1 are zero; he could benefit by increasing $s$. We therefore ask whether some side payment $s \leq 1 / 3$ eliminates asymmetric equilibria in period 1 , and assures approval of the agenda setter's proposal in period 1 . And if such an $s$ exists, we determine its minimum value.

Consider the decision of some legislator in period 1. In an equilibrium with asymmetric pure strategies some legislator, whose vote is decisive, votes no. In voting yes he obtains $-1 / 3(1+\delta)+s+\delta / 3$; voting no yields $-\delta / 3+\delta / 6$. A yes vote is advantageous if and only if $s \geq(2-\delta) / 6$. Notice that $(2-\delta) / 6$ strictly decreases in $\delta$, and lies in the interval $[1 / 6,1 / 3]$. The more important the future, the more valuable the future benefits of membership in the minimum winning coalition, and the easier it is for the agenda setter to sway the legislator. Moreover, for any $\delta>0$, some feasible payment yields the agenda setter strictly positive payoffs in period 1 , and induces legislators to vote yes. Thus, equilibria with asymmetric pure strategies in period 1 which reject the agenda setter's

\footnotetext{
${ }^{15}$ Asymmetry requires identical legislators to behave differently. In the setting of the previous section no underlying asymmetry allows legislators to coordinate and generate a particular form of asymmetric behavior. A sequential voting procedure could model such an asymmetry in a natural way. This extension is considered in Subsection 4.2.
} 
proposal disappear.

To show that this strategy of the agenda setter and unanimous approval in period 1 are an equilibrium, it remains to consider a given legislator who is not decisive. As the vote does not change the outcome in period 1, but increases the legislator's chances of belonging to the minimum winning coalition in period 2, for any $s$ he strictly prefers to vote yes.

Thus, it is optimal for the agenda setter to offer $s=(2-\delta) / 6$. This value is the smallest payment that in period 1 makes it a (weakly) dominant strategy for each legislator to vote yes. As a result, it precludes legislators from coordinating on an asymmetric equilibrium in period 1 .

The above strategies thus constitute a subgame perfect equilibrium. We summarize with

Proposition 2 Suppose legislators respond to the exclusion strategy (for small s) by playing asymmetric pure strategies in period 1. Then a subgame perfect equilibrium exists in which

- the agenda setter plays the exclusion strategy with $s=(2-\delta) / 6$ and

- in period 1 the legislature unanimously approves the agenda setter's proposal; in period 2 a minimum winning coalition approves the proposal the agenda setter makes in that period.

\subsection{Agenda-setting power when each vote is decisive}

The equilibria described in Propositions 1 and 2 base the agenda setter's exclusion strategy on two characteristics. First, in equilibrium no individual legislator is decisive and therefore cannot block the proposal in period 1. Second, the agenda setter can condition future benefits or political exclusion on votes in period $1 .^{16}$ To show that what drives our result is the second characteristic, we modify our previous assumptions and suppose that voting is sequential, with voting order $1,2,3$. As before, assume that the agenda setter plays the exclusion strategy. Sequential voting does not change the incentives in period 2 , and in period 2 a minimum winning coalition will vote yes.

\footnotetext{
${ }^{16}$ Under a secret ballot future benefits or political exclusion cannot in principle be conditioned on votes cast in period 1. Subsection 5.2 discusses conditions under which Proposition 1 continues to hold.
} 
Suppose the agenda setter sets low payments, say $s=0$. Then in period 1 a legislator votes no if and only if he is decisive. Therefore, legislator 1 votes yes, and free rides on the no votes of the other two legislators.

On the other hand, Proposition 2 already showed that sufficiently high payments in period 1 make it a (weakly) dominant strategy for each legislator to vote for the proposal in period 1 . We thus have the result that under sequential voting, a subgame perfect equilibrium exists in which the agenda setter plays the exclusion strategy with $s=(2-\delta) / 6$ and in period 1 the legislature votes unanimously for the agenda setter's proposal; in period 2 a minimum winning coalition supports the proposal the agenda setter makes in that period. A comparison to Proposition 1 shows that sequential voting benefits legislators, but does not eliminate the agenda setter's power.

Still, in the period 1 voting situation described in the previous paragraph the legislature unanimously supports the agenda setter's proposal, so it is not true that each yes vote is decisive. To show that our results do not depend on the fact that in equilibrium no individual legislator is decisive, suppose that legislator 1 , who is first in the voting order, votes no. This could happen because he made a mistake or because a small benefit in the future may not suffice to induce him to vote yes in period 1. He may have "non-consequentialist" motivations, for example, because he wishes to express a preference through the act of voting. ${ }^{17}$ But because the agenda setter plays the exclusion strategy with $s=(2-\delta) / 6$ it is a (weakly) dominant strategy for remaining legislators to vote yes in period 1. Thus, the proposal is adopted and each yes vote is decisive. In particular, when the last legislator in the voting order casts his vote, he has observed the earlier votes and knows that the outcome depends on his vote.

\subsection{Agenda-setting power and a legislator's pivotal prob- ability}

The analysis above presented two types of voting profiles. In the equilibrium of Proposition 1 all legislators vote yes in period 1 and no legislator is decisive; in the equilibrium at the end of Subsection 4.2 two legislators vote yes and both legislators are decisive. On the other hand, whereas the first situation requires no side payments, the second does and therefore limits agenda-setting power.

\footnotetext{
${ }^{17}$ See Shayo and Harel (2012) for an overview and experimental evidence for this voting behavior.
} 
To show that side payments monotonically increase (and agenda-setting power monotonically decreases) with a legislator's pivotal probability, we suppose, in line with our assumption in Subsection 4.2, that for some legislator a small benefit in the future may not suffice to induce him to vote yes in period 1. Assume that it is common knowledge that with probability $p$ one of the legislators, say legislator $A$, has a "non-consequentialist" attitude and rejects the proposal. If the proposal in period 1 is approved, the other two legislators are pivotal, and so $p$ also measures the pivotal probability. ${ }^{18}$

Consider one of the other two legislators, say $B$, and assume he expects the other legislators to vote yes, unless legislator $A$ has a "non-consequentialist" attitude. In this case he only expects $C$ to vote yes. With probability $p$ he is in the same voting situation as at the end of Subsection 4.2; with probability $1-p$ the situation is similar to Proposition 1. More precisely, voting yes yields

$$
p\left(-\frac{1}{3}(1+\delta)+s+\frac{\delta}{3}\right)+(1-p)\left(-\frac{1}{3}(1+\delta)+s+\frac{\delta}{3} \frac{2}{3}\right)
$$

voting no implies

$$
p\left(-\frac{\delta}{3}+\frac{\delta}{3} \frac{1}{2}\right)+(1-p)\left(-\frac{1}{3}(1+\delta)+s\right) .
$$

Hence, each of the two legislators prefers to vote yes in period 1 if and only if

$$
s \geq \tilde{s}(p) \equiv \max \left\{\frac{2-\delta}{6}-\frac{1-p}{p} \frac{2 \delta}{9}, 0\right\} .
$$

The threshold $\tilde{s}(p)$ increases monotonically in the pivotal probability $p$, until the payments of Proposition 2 are reached. Notice also that for low values of the pivotal probability, $\tilde{s}(p)$ is constant and zero. Therefore the assumption of completely consequentialist voters who are solely motivated by preferences over policy outcomes can be somewhat relaxed without affecting the result in Proposition 1.

\subsection{Observations}

Several comments are in order.

\footnotetext{
${ }^{18}$ The alternative assumption that with probability $p$ any of the three legislators has "nonconsequentialist" motivations yields qualitatively the same results. The exposition, however, is more complex because $p$ no longer measures the pivotal probability.
} 
First, in the above equilibria a legislator's expected benefit is $-1 / 3(1+\delta)+$ $\tilde{s}(p)+\delta 2 / 9$. Given the size of the different payments $\tilde{s}(p)$, legislators obtain lower expected payoffs than were both proposals rejected. In period 1 all legislators vote for a policy that hurts all of them.

Second, exploitation is most severe under the conditions of Proposition 1, and exploitation declines with a legislator's pivotal probability. So agendasetting power is sensitive to the institutions and behavioral conditions under which agenda setting takes place. Later sections further analyze the sensitivity of our conclusions to variations of our assumptions. The monotonicity of side payments in the pivotal probability suggests that agenda setters are more powerful in large legislatures, but these issues are not explicitly modeled here.

Third, in the equilibrium of Proposition 1 no legislator is decisive; in contrast, in the equilibrium at the end of Subsection 4.2 two legislators vote yes in period 1, and both legislators are decisive. Thus, the indifference of a legislator who is not decisive strengthens our result, but is not crucial for unanimous approval in period 1 .

Fourth, in the basic model (under the conditions of Proposition 1) legislators do not have a dominant strategy and thus do not find themselves in a multilateral prisoners' dilemma (in which fixing the action of one player, the others are in a prisoners' dilemma). But side payments increase the incentives for defection, thereby allowing the agenda setter to eliminate the equilibrium with asymmetric voting.

Fifth, crucial for unanimous approval is the agenda setter's ability in period 2 to reward a legislator who voted yes in period 1. A unanimity rule in period 2 breaks this link between the periods because then in period 2 every vote is needed and no legislator can be excluded. On the other hand, any scarce resource controlled by the agenda setter and valued by legislators could establish such a link. In some situations it is reasonable to interpret the President as the agenda setter. Rewards could then consist, for example, of invitations to the White House, fundraisers, or campaign appearances. In other situations one might think of party leaders as agenda setters, with rewards consisting of committee assignments and money from political action committees to reelection campaigns, which are controlled by party leaders.

Sixth, the result in Proposition 1 does not require that the agenda setter punish with certainty a legislator who voted no in period 1 . It suffices that 
in period 2 the agenda setter can exclude a legislator with a small but strictly positive probability. This result can reconcile the view by historians that Joseph Cannon, as Speaker of the US House of Representatives, exercised power by punishing opponents, with the findings by Krehbiel and Wiseman (2001) that in making committee appointments Cannon did not consistently reward supporters or punish opponents. For, as shown above, what matters is that when a legislator is not decisive, the cost to him of voting for a policy he dislikes is small or even zero, so that if he expects even a small gain from membership in the winning coalition in a future period, he will support the agenda setter's policy. Strong loyalty can appear under weak punishments and rewards.

Seventh, the exclusion strategy which allows the agenda setter to exploit the legislators in period 1 can also be used by the agenda setter to maintain power. Suppose that in some period before the final one a motion is made to depose the agenda setter. The incumbent agenda setter can threaten that if he stays in power, then in the final period he will give preference for membership in the minimum winning coalition to any legislator who had voted against the motion. Then as in the previous analysis, it is a Nash equilibrium for all legislators to vote to retain the agenda setter, even though he had exploited them and may exploit them in the future.

Eighth, it is not strictly necessary that the agenda setter's proposal cannot be amended in any period. What is critical is that in the final period his proposal cannot be amended. For in any non-final period, the agenda setter can use the exclusion strategy against any legislator who proposes an amendment, and against any legislator who votes for an amendment. In the final period, if the agenda setter's proposal cannot be amended, he can indeed implement the exclusion strategy, punishing legislators who had voted against him.

Ninth, although we spoke of forming a minimum winning coalition in period 2 , similar results can appear when in period 2 the agenda setter is very busy, willing to help legislators with their legislative needs, but giving priority to legislators who had supported him in the past.

Lastly, the benchmark result continues to hold under more general conditions, among them larger legislatures or legislators who value the future differently. ${ }^{19}$ The next section examines further institutions that do not limit the

\footnotetext{
19 For large legislatures see Subsection 5.3; for heterogeneous legislators details are available upon request.
} 
agenda setter's power. Section 6 considers institutions that do.

\section{Institutions that do not limit the agenda set- ter's power}

Some institutional arrangements, such as secret voting, may at first sight appear to restrict greatly, or even to eliminate, the agenda setter's power. We show, however, that they do not.

\subsection{Term limits and turnover}

One might expect that term limits and turnover reduce the agenda setter's ability to punish or reward legislators. For that result to hold, however, the end of the legislators' terms must be soon and certain.

Suppose that each district might be represented in period 2 by a different legislator. That is, each legislator in period 1 continues only with some probability in period 2. The result in Proposition 1 is robust, because conditional on continuing to serve, a legislator who votes yes in period 1 enjoys higher expected utility over the two periods than he would by voting against.

Suppose now that between the two periods the identity of the agenda setter may change. More precisely, assume that the probability the agenda setter in period 1 continues is $q$. With probability $1-q$ in period 2 some other person makes a proposal which is unrelated to voting in period 1 , and yields benefits $\pi$ to the legislator whose votes will be analyzed below.

Let the agenda setter in period 1 use the exclusion strategy. If the agenda setter continues in period 2 , his proposal in period 2 will be accepted by a minimum winning coalition.

Consider now a given legislator in period 1, and suppose that all other legislators vote yes. Again, a single vote does not affect the collective decision and the proposal is approved. A legislator who votes yes obtains $-1 / 3(1+\delta)+$ $\delta(2 q / 9+(1-q) \pi)$, whereas voting against yields $-1 / 3(1+\delta)+\delta(1-q) \pi$. The difference is $\delta q 2 / 9>0$. When $q=1$ the trade-off discussed in Section 4 applies. But for any strictly positive probability that the agenda setter continues to serve, a legislator strictly prefers to vote yes in period 1.

If in period 1 each legislator expects all others to vote no, no single vote would 
change the outcome of the collective decision which rejects the proposal. But by voting yes a legislator can ensure his membership in the minimum winning coalition in period 2 if the agenda setter continues. Thus, each legislator strictly prefers to vote yes in period 1 , and it is not an equilibrium for each legislator to vote $n o$.

Consider now term limits. Term limits which make a legislator leave before the agenda setter leaves mean that the legislator will not vote for a policy that benefits the agenda setter. ${ }^{20}$ Speaking loosely, term limits may weaken the power of the agenda setter. Instead, the agenda setter would have to form a minimum winning coalition of beneficiaries in each period. ${ }^{21}$

A term limit applying to the agenda setter corresponds to $q=0$ in the analysis above. ${ }^{22}$ Even in this case, the legislators can be exploited. Suppose the current agenda setter will never serve again, but that some current member of the legislature serves as the agenda setter in the future. The current agenda setter can still propose a policy that benefits himself greatly, while giving nothing to all but one legislator. Let the current agenda setter propose a policy that gives benefits to himself and to one other legislator, say P, who may become the agenda setter in period 2. Legislator $\mathrm{P}$ would then gain from threatening that when he becomes the agenda setter, he will propose no benefits to any legislator who votes against the benefits proposed to $\mathrm{P}$ in period 1 . It is therefore an equilibrium for all legislators to vote yes in period 1 , and it is not an equilibrium for all to vote no.

\subsection{Secret ballots}

The agenda setter can exploit legislators even if they vote by secret ballot. Under a secret ballot the agenda setter does not know who voted against him, and so cannot later punish a particular defector. It appears that any one legislator

\footnotetext{
${ }^{20}$ Actually, the legislator is indifferent and might as well vote yes. Proposition 1 is therefore robust, in the sense that it is still an equilibrium to approve the first proposal, and a minimum winning coalition approves the proposal in period 2.

${ }^{21}$ Whereas federal congressmen and senators in the U.S. face no term limits, some states do impose term limits for state legislators. Given that these limits are often longer than eight years, they do not seem to restrict the agenda setter's power so much that he must form a minimum winning coalition of beneficiaries in each period.

${ }^{22}$ Office holders may believe that a term limit will not be applied. An example of extending term limits is mayor Michael Bloomberg of New York City who won election to a third term.
} 
would want to vote no in period 1 , and it appears that he would want to do so if with even a small probability he will be decisive. But suppose that each legislator faces a risk of not serving in period 2. The agenda setter can then threaten to give priority to new legislators in period 2 if the vote in period 1 is not unanimous. That is, in period 2 the minimum winning coalition would include all new legislators, and (if needed) some continuing legislators. Each legislator in period 1 who expects others to vote yes has an incentive to vote yes. Turnover can increase the agenda setter's power.

The following formalizes this idea. Let a legislator continue in period 2 with probability $q$. As before, in period 2, each member of the minimum winning coalition gains by voting yes, and the proposal will be adopted. The probability that a legislator belongs to the minimum winning coalition in period 2, conditional on his continuing to serve, is $p^{C} \equiv 2 q^{2} / 3+\left(1-q^{2}\right)$ when members of the minimum winning coalition are chosen first from continuing legislators, and $p^{N} \equiv 2 q^{2} / 3+(1-q) q$ when new legislators have priority in becoming members of the minimum winning coalition.

Consider a given legislator in period 1 and suppose that all other legislators vote no. In voting yes he obtains $-(1+\delta q) / 3+q \delta p^{C} / 3$. A legislator who votes no does not reduce his tax payments, but does cause the agenda setter to give priority to new legislators, yielding the legislator expected benefits of $-(1+\delta q) / 3+q \delta p^{N} / 3$. Given that $p^{C}>p^{N}$, the difference is strictly positive; thus, a legislator strictly prefers to vote yes in period 1 .

Could a symmetric Nash equilibrium in pure strategies have all legislators in period 1 vote no? Denote by $x$ the number of no votes in period 1. Suppose the agenda setter threatens that in forming the minimum winning coalition in period 2 he will give priority to new legislators with probability $r(x)$. Assume further that $r(x)$ strictly increases with $x$. The agenda setter is willing to follow such a strategy, because it costs him nothing. Consider period 1 and suppose all legislators vote no. Again a single vote does not affect the collective decision which rejects the proposal. But a legislator who votes yes increases the chances that a continuing member will belong to the minimum winning coalition. Hence, conditional on continuing to serve, a legislator's expected utility in period 2 is

$$
\frac{1}{3} \delta\left(-1+(1-r(x)) p^{C}+r(x) p^{N}\right) .
$$

The legislator will have to pay taxes in period 2, and his chances of belonging 
to the minimum winning coalition decline with $r(x)$. Voting yes makes $x=2$, whereas voting no makes $x=3$. The legislator strictly prefers to vote yes if and only if $r(3)>r(2)$. Hence, a legislator strictly prefers to vote yes in period 1; unanimous opposition is not an equilibrium.

\subsection{Large legislatures, and partisan benefits}

Consider the agenda setter's power when the legislature consists of more than three members. For simplicity let the number of legislators, $n$, be an odd number. ${ }^{23}$ As before, assume simple majority voting, and let the agenda setter play the exclusion strategy. Again, a minimum winning coalition will support his proposal in period 2 .

Consider period 1. Suppose all legislators vote yes, so that no individual vote is decisive. The expected utility of a legislator who votes yes is $-(1+$ $\delta) / n+\delta(n+1) /\left(2 n^{2}\right)$. The first term is the taxes paid in both periods, as both proposals are approved. The second term represents the expected value of obtaining $\delta / n$ with probability $(n+1) /(2 n)$. Voting no in period 1 yields $-(1+\delta) / n$. The difference $\delta(n+1) /\left(2 n^{2}\right)$ is strictly positive. Again, a legislator will strictly prefer to vote yes in period 1: it is an equilibrium for each legislator to vote yes in period 1 . The agenda setter benefits from larger legislatures, as $(n+1) /(2 n)$, the share of the surplus given to the minimum winning coalition in period 2, decreases with $n$.

As in our previous analysis, in period 1 this is the unique robust equilibrium with symmetric pure strategies. A legislator who expects all others to vote no strictly prefers to vote yes, because his vote does not change the outcome but assures the legislator of belonging to the minimum winning coalition in period 2. Voting no makes him belong to this coalition with the smaller probability $(n+1) /(2 n)$.

Large legislatures allow us to consider super-majority rules. As now approval of the proposal in period 2 requires more legislators, the agenda setter can extract a smaller surplus in period $2 .{ }^{24}$ It can be shown, however, that if the

\footnotetext{
${ }^{23}$ This assumption simplifies the exposition. Proposition 1 extends to even-sized legislatures with at least four members requiring $n / 2+1$ votes for approval. A two-person legislature is special: majority rule effectively becomes a unanimity rule and each legislator is decisive.

${ }^{24}$ In the context of Proposition 1, the agenda setter makes no payments in period 1 . With more than three legislators the payments in period 1 in the context of Proposition 2 become $1 / n-\delta(n-m) /(n(n-m+1))$, where $m$ is the number of yes votes necessary for approval.
} 
majority requirement is less than unanimity, the preceding argument applies, and in period 1 all legislators vote for a policy that hurts all of them.

The results continue to hold when the agenda setter restricts benefits to members of the majority party. Suppose a majority party has $n$ members and a minority party has $m$ members, with $n>m+2 .{ }^{25}$ Minority party members expect to be excluded from a future minimum winning coalition because the agenda setter plays the exclusion strategy, but promises future benefits only to members of the majority party. ${ }^{26}$ The analysis described at the beginning of this section can be applied, and so the following constitutes a subgame perfect equilibrium: the agenda setter plays the exclusion strategy restricted to members of the majority party; the proposal in period 1 is approved with the votes of the majority party; the agenda setter's proposal in period 2 is approved by a minimum winning coalition (excluding at least one member of the majority party).

Partisan behavior makes our assumption of a finitely repeated game (rather than of an infinitely repeated game) seem appropriate. An election after period 2 might change the majority party and the agenda setter. In the next term the new agenda setter and legislature might play a similar subgame perfect equilibrium.

\section{Overcoming the agenda setter's power}

Some institutional arrangements, such as entitlements, may reduce the agenda setter's power by reducing his discretion, and other factors can increase a legislator's ability to resist exploitation.

\subsection{Tacit collusion against the agenda setter}

In the two-period model the agenda setter exploits the legislature. Such exploitation raises the question whether legislators can somehow agree on rejecting exploitive proposals completely. We show now that if the legislators are expected to punish deviations appropriately, then tacit collusion against the

\footnotetext{
These payments increase with $m$.

${ }^{25}$ For simplicity take $n$ to be an odd number.

${ }^{26}$ Speaker Joseph Cannon, mentioned above, appeared to follow this strategy, in allowing the leader of the minority party to appoint the minority members of committees. See Finocchiaro (2002).
} 
agenda setter might occur. To allow for such an agreement consider a repeated game: in each period the game continues with positive probability. Suppose also that at the beginning of each period all players know whether the game will continue after that period. ${ }^{27}$ As usual, this framework admits a multiplicity of equilibria and very different outcomes can be sustained; we will see that when legislators cannot reach an agreement, they might be exploited in every period.

Suppose that in each period, the game ends with probability $1-\delta>0$, and continues with probability $\delta>0$. Whether period $t$ is the final one is revealed to all players at the beginning of period $t$, before a proposal is made. The same agenda setter makes proposals in all periods.

The agenda setter modifies the exclusion strategy in the following way. In all but the final period he proposes to retain the whole budget for himself and threatens that in the final period he will exclude any legislator who had earlier voted against a proposal the agenda setter had made. In the final period, the agenda setter proposes to split the benefits equally with the members of a minimum winning coalition. All legislators who supported him in all periods before the final one have an equal chance of belonging to the minimum winning coalition in the final period. If a minimum winning coalition requires more members than the number of legislators who supported all proposals before the final period's proposal, then the remaining members are chosen, taking into account the number of times each legislator had voted for the agenda setter's proposals. That is, the two legislators with the most yes votes participate with probability 1 (in case of ties, equal probabilities are assigned).

Consider the following strategy profile for each of the three legislators. In the final period each legislator votes yes if and only if he belongs to the minimum winning coalition. Consider non-final periods. In the first period each legislator votes no. Each legislator continues to vote $n o$ in any non-final period $t$ as long as all legislators had voted no in all previous periods. If at least one legislator voted yes in the past, then all legislator approve the next $K$ proposals. So punishment requires the approval of $K$ non-final proposals. These are the symmetric pure voting strategies in Proposition 1.

Consider the final period. Again, a minimum winning coalition will approve

\footnotetext{
${ }^{27}$ Tacit collusion can also be sustained under a finite horizon of at least three periods. But this requires asymmetric behavior of symmetric legislators, see Appendix A.2.
} 
the proposal the agenda setter makes.

Consider a non-final period $t$, with all legislators voting no (that is, they cooperate). Doing so yields zero payoffs in all non-final periods and $-1 / 9$ in the final period; and because with probability $1-\delta$ period $t+1$ is the final period, with probability $\delta(1-\delta)$ period $t+2$ is the final period, and so on, a legislator's expected payoff is

$$
-\frac{1}{9}\left((1-\delta)+\delta(1-\delta)+\delta^{2}(1-\delta)+\ldots\right)=-\frac{1}{9} .
$$

Now suppose that one legislator votes yes in period $t$ (that is, he defects). Notice that the payoff in period $t$ is still zero, as the proposal is rejected by the majority. Because the consequence is punishment from fellow legislators, in the next $K$ non-final periods the payoff is $-1 / 3$. The reward is certain membership in the minimum winning coalition yielding zero payoffs in the final period, because the deviator maintains a lead of one yes vote over the fellow legislators in all subsequent periods. Because with probability $\delta$ period $t+1$ is a non-final period, with probability $\delta^{2}$ period $t+2$ is a non-final period, and so on, a legislator's expected payoff is

$$
-\frac{\delta}{3}\left(1+\delta+\delta^{2}+\cdots+\delta^{K-1}\right) .
$$

Cooperation is thus sustainable if and only if

$$
3 \delta \frac{1-\delta^{K}}{1-\delta} \geq 1
$$

This inequality holds if the discount factor is large enough, because then it is sufficiently unlikely that the game ends soon, and thus the threat of punishment is sufficiently severe. Because the left-hand side increases with $K$, a longer length of punishment can sustain cooperation for lower discount factors.

The agenda setter cannot reduce the sustainability of tacit collusion through increased side payments. In the first period a single deviation cannot trigger side payments, as the proposal is still rejected. In later periods the proposal is approved as part of the punishment, and side payments cannot be credibly offered. ${ }^{28}$

\footnotetext{
${ }^{28} \mathrm{~A}$ natural extension of the equilibrium with symmetric pure strategies in period 1 has each legislator in the final period vote yes if and only if he belongs to the minimum winning coalition, and in non-final periods each legislator votes yes. So payoffs in non-final periods are $-1 / 3$, and in the final period $-1 / 9$. If, however, a legislator deviates and votes no in any
} 
Thus, when the future is sufficiently important, legislators who use a grim trigger strategy can eliminate exploitation completely. Other behavior, however, is also possible, including the approval of exploitive proposals in every period but the final one.

\subsection{Counter-threats}

The analysis so far had the agenda setter threaten legislators with political exclusion, and allowed a legislator to take only one action-vote. A legislator might, however, react to the exclusion strategy with $s=0$ by making a counter-threat to exclude the current agenda setter if the legislator in question later becomes the agenda setter. The following enriches the basic model to capture this possibility; we show that in equilibrium the legislators will still be exploited - albeit less than if different agenda setters, serving for two periods each, each play the exclusion strategy with $s=0$.

Let the legislature consist of five members, with one of them the agenda setter, and with all paying taxes and voting. Voting occurs over two legislative terms, each consisting of two periods. Legislator 1 is the agenda setter in the first two periods; each of the other four legislators is equally likely to be the agenda setter in the following two periods. ${ }^{29}$

Given our assumption of uncertainty over the future agenda setter and the symmetry among legislators who are not the agenda setter in period 1, let each react to the exclusion strategy with $s=0$ by making the following counterthreat: if the agenda setter in period 1 does not make a payment of $s$ in period 1 , he will be excluded from the minimum winning coalition in period 4 in case the legislator making the threat becomes the agenda setter in period 3 . If the agenda setter makes the requested payment he will belong to the minimum winning coalition in period 4 with certainty. ${ }^{30}$

non-final period, he does not affect policy and payoffs in non-final periods, but is punished by the agenda setter in the final period, obtaining only $-1 / 3$. The difference is $2 / 9>0$, the analogue of the difference in the context of Proposition 1 that now takes into account the infinite horizon.

${ }^{29}$ Excluding the possibility of legislator 1 being the agenda setter in the second term makes the counter-threat more credible and exploitation in the first term more difficult.

${ }^{30}$ Again, the agenda setter is assumed to treat each legislator equally, which is here motivated by the uncertainty over the identity of the next agenda setter. Assuming that the agenda setter of the second term is known and that payments in period 1 can be individualized would not affect exploitation in period 1 , but would affect the distribution within the 
Proceeding by backward induction, consider the last period. Notice that even if the two agenda setters are both certain to belong to the minimum winning coalition in the last period, one slot is still open, and the second agenda setter can appropriately reward votes that had been cast in period 3. Note also that the second agenda setter is willing to exclude or to include the agenda setter of periods 1 and 2 in the last period's minimum winning coalition because this costs him nothing. Thus, it is an equilibrium for the second agenda setter to play the exclusion strategy with $s=0$, for the proposal he makes in period 3 to win unanimous approval, and for the proposal he makes in period 4 to be approved by a minimum winning coalition that includes the first agenda setter.

Consider the first term, or periods 1 and 2. The preceding makes it clear that for any exclusion strategy, an equilibrium exists in which the legislature approves the proposals made in periods 1 and 2 .

Consider the first agenda setter; call him A1. Suppose that A1 ignores the threat, so that $s=0$ and that A1 will be excluded from the minimum winning coalition in period 4. On the other hand, if A1 gives in, he is assured of belonging to the minimum winning coalition in period 4 , at a cost of $s$. Giving in is better if and only if $-4 s+\delta^{3} / 5 \geq 0$, which is equivalent to $s \leq \delta^{3} / 20$.

The optimal counter-threat thus has $s=\delta^{3} / 20$. The above strategies thus constitute a subgame perfect equilibrium. We summarize with

Proposition 3 With two terms and a change in agenda setters, a subgame perfect equilibrium exists in which:

In the first term

- the agenda setter plays the exclusion strategy with $s=\delta^{3} / 20$ and

- in period 1 the legislature unanimously approves the agenda setter's proposal; in period 2 a minimum winning coalition approves the proposal the agenda setter makes in that period.

In the second term

- the agenda setter plays the exclusion strategy with $s=0$ and

- in period 3 the legislature unanimously approves the agenda setter's proposal

legislature. 
- in period 4 a minimum winning coalition which includes the first agenda setter approves the proposal the agenda setter's proposal in that period.

A counter-threat benefits the legislators, but the first agenda setter still obtains at least $4 / 5$ of the period 1 benefits.

\subsection{Entitlements}

One may think that the agenda setter necessarily gains from committing future policy. But here the opposite occurs. Suppose that whatever policy is adopted in period 1 will also hold in period 2. Roughly speaking, instead of policies subject to annual appropriations, we can think of entitlements which remain in force unless explicitly changed. Then in period 1 the agenda setter could no longer threaten to punish in period 2 a legislator who voted no in period 1 . The best the agenda setter could do in period 1 is to propose a policy that gives zero net benefits to members of the minimum winning coalition; that generates lower benefits to the agenda setter than he could obtain if he had set the agenda in both periods.

A different question is behavior if the policy adopted in period 1 continues in force in period 2, unless the agenda setter proposes an amendment, which the legislature supports; that is, the default policy in period 2 is the policy adopted in period 1, rather than no spending and no taxes in period 2. If in period 1 the legislature adopted a policy that gives all benefits to the agenda setter, in period 2 the agenda setter of period 1 would not want to change the policy. By assumption, only the agenda setter in period 1 can propose a new policy in period 2. Therefore, in period 1 no legislator would support the policy that gives himself negative benefits in period 1 . The agenda setter does best in period 1 by proposing a policy that generates zero net benefits to each member of the minimum winning coalition. Put differently, the agenda setter would prefer annual appropriations over entitlements: the default policy strongly affects the agenda setter's power.

\subsection{Separation of budgetary powers}

Our results do not require that in each period the decisions on taxation and spending are bundled. But if they are not bundled, they require that funds are already approved. 
Let spending in each of the two periods be fixed at one dollar, so that the three legislators vote only on how to allocate the dollar. ${ }^{31}$ In any period in which the proposal is rejected, each legislator gets zero benefits. Assume that the agenda setter plays an exclusion strategy in which he offers in period 2 a small benefit $b>0$ to members of the winning coalition.

In period 2 , no member of the minimum winning coalition gains from voting no, and the legislature passes it. Consider now a given legislator in period 1 , with all other legislators voting yes. When the legislator in question votes yes he gets $b \delta 2 / 3$, whereas in voting no he gets nothing. Thus, a legislator strictly prefers to vote yes in period 1 , and it is an equilibrium for each legislator to vote yes. $^{32}$

Could a Nash equilibrium in symmetric pure strategies have all legislators in period 1 vote $n o$ ? If they do, a legislator who votes yes will belong to the minimum winning coalition in period 2 , obtaining $b \delta$. Voting no reduces the chance of belonging to the minimum winning coalition in period 2 , so that total payoffs are $b \delta 2 / 3$. Thus, a legislator strictly prefers to vote yes in period 1 ; it is not an equilibrium for all legislators to no.

Put differently, the agenda setter would prefer separation of budgetary powers over combined taxation and spending decisions. But suppose that in period 2 the vote on taxes is held before the vote on spending. We just saw that the agenda setter will offer to give very little of the spending to each member of the minimum winning coalition. So all legislators, anticipating that, vote against the tax. The agenda setter would then be unable to exploit in period 1 .

\section{Conclusion}

It is well known that an agenda setter enjoys power which he can use to his own benefit. But this paper showed much more, suggesting that by using promises and threats the agenda setter in the initial period can gain all the benefits from legislation, impose large costs on all legislators, while getting large majorities to support such a selfish policy. So broad support for a policy need not mean wide benefits from that policy.

\footnotetext{
${ }^{31} \mathrm{An}$ analogous result holds if an entitlement program sets benefits to all legislators, but in each period the legislature decides how to allocate taxes among its members.

${ }^{32}$ A technical issue concerns the existence of the optimal amount to offer. That may be solved by making the realistic assumption that a smallest monetary unit exists.
} 
Conventional wisdom defines agenda-setting power as "the ability to make proposals that are difficult to amend" (see e.g. Tsebelis and Garret 1996). Most of the paper made the benchmark assumption that the agenda setter has such absolute power. Not surprisingly, when this formal power is reduced (such as when any one agenda setter serves for a limited time) exploitation is reduced.

The extreme assumption concerning the formal power of the agenda setter allowed us to identify two additional informal conditions for exercising power. First, power depends on the ability to reward and punish legislators, requiring discretion or the ability to allocate future benefits. Entitlements remove discretion completely. Exercising power also requires that the agenda setter identify supporters in early periods. Though a secret ballot makes identification impossible, we showed that when terms are staggered and legislators run for re-election at different times (as in the U.S. Senate) the agenda setter's power is restored. Second, power depends on an individual legislators' incentives to resist exploitation. These incentives increase with the likelihood that a vote is decisive, which likelihood is maximized under sequential voting; the incentives to resist exploitation can also be sustained through tacit collusion by the legislators, though other behavior is also possible.

Agenda-setting models can also apply to an autocrat in a nondemocratic regime, because even an autocrat needs support for his policies from some, say the political elite (see e.g. Diermeier and Fong 2011). With such an interpretation, our analysis implies that the autocrat might be less constrained in exploiting the elite than commonly thought. Moreover, the autocrat prefers that his future power be restricted. For an autocrat with dictatorial powers in the final period could not credibly promise future rewards, and would get little benefits in earlier periods. Paradoxically, the expectation of more formal power endows the proposer with less real power. Put differently, weakness creates strength.

Our model can also apply to special interest politics. Suppose a special interest group promises to give the agenda setter ten thousand dollars if the legislature approves a policy that benefits the special interest, but harms the legislators. The agenda setter uses his exclusion strategy to get the policy passed. This strategy can explain the puzzle of the surprisingly small rentseeking expenditures by special interest groups, first noted by Tullock (1972).

Similar strategies can be used by a party leader to ensure the support of 
party members. An incumbent can incentivize loyalty of potential successors in a current period by promising all candidates a chance of becoming his political heir. Such an approach appears to have been used in 2013 by the head of the Bavarian Government and ruling party, who refused to name his successor, but instead kept alive the prospects of several candidates. The same approach was used by prime minister Aznar in Spain.

The qualitative effects of our model can explain some stylized facts. For example, the agenda setter does better for himself, and garners stronger majorities, in earlier periods of power than in his final term. That fits the pattern of a lame duck president losing power. The results can also explain why an agenda setter may not constrain future policy; the ability to change policy in the future is precisely what gives the agenda setter the ability to threaten legislators in earlier periods. And our analysis is consistent with the observation that a legislative district may get more benefits the more closely allied are its representatives with the agenda setter (which can be a political party controlling the central government). Evidence from the United States (see Larcinese, Rizzo and Testa 2006), Spain (see Solé-Ollé and Sorribas-Navarro 2008), Israel (see Rozevitch and Weiss 1993), Brazil (see Brollo and Nannicini 2012), and Japan (see Tamura 2010) show that local governments under the control of the same party as the central government receive higher transfers from the central government.

The results of this paper can be viewed in at least three ways. First, the results could explain the power that some agenda setters possess, as exemplified by Speaker Cannon discussed in the Introduction. Second, the results can be viewed as predicting that because an agenda setter can exercise so much power, institutions may arise to limit such power. That indeed happened when the House of Representatives changed its internal rules to reduce Speaker Cannon's power. Or, a legislature may allow amendments from the floor. And the existence of multiple agenda setters, each in a different area, can reduce agendasetting power: if it will be long before the next time that area turns up, then the agenda setter in that area must offer a large side payment for legislators to approve his proposal.

Third, the results can suggest that though an agenda setter has the power to induce a legislature to adopt policies which benefit him alone, agenda setters often have goals other than personal benefits. Earlier we had discussed how 
an agenda setter may favor members of his own party. Or, as Margolis (1984) suggests, political leaders may be altruistic at least in part, aiming to further the public good, or to go down in history as benefactors of the country. 


\section{A Appendix}

\section{A.1 Mixed-strategy equilibria in the benchmark}

Under majority rule, the equilibrium in period 1 can also have each legislator vote yes with positive probability less than 1. A mixed strategy allows for trading off the increased chance of belonging to the minimum winning coalition in period 2 with the increased probability that an exploitive policy is approved in period 1. This appendix explores, analogously to Proposition 2, the conditions under which a mixed-strategy equilibrium exists, and investigates whether the agenda setter can offer sufficient side payments $s$ to induce the equilibrium in Proposition 1.

Consider a given legislator and suppose the other two legislators vote yes with probability $x$. The increase in a legislator's chances of belonging to the minimum winning coalition in period 2 when he votes yes is greater the more often the realizations of the other legislators' mixed strategies in period 1 specify a no vote. More precisely, expected payoffs are given by

$x^{2}\left(-\frac{1}{3}+s+\delta\left(\frac{2}{9}-\frac{1}{3}\right)\right)+2 x(1-x)\left(-\frac{1}{3}+s+\delta\left(\frac{1}{3}-\frac{1}{3}\right)\right)+(1-x)^{2} \delta\left(\frac{1}{3}-\frac{1}{3}\right)$,

which simplifies to

$$
-\frac{1}{3}\left(2 x-x^{2}+\frac{x^{2} \delta}{3}\right)+s x(2-x) .
$$

On the other hand, a legislator who votes no in period 1 has a chance of belonging to the minimum winning coalition in period 2 only when at least one other legislator votes no, in which case the proposal in period 1 is rejected. Expected payoffs are thus

$$
x^{2}\left(-\frac{1}{3}+s-\frac{\delta}{3}\right)+2 x(1-x) \delta\left(\frac{1}{6}-\frac{1}{3}\right)+(1-x)^{2} \delta\left(\frac{2}{9}-\frac{1}{3}\right),
$$

which simplifies to

$$
-\frac{1}{3}\left(x^{2}+\frac{\delta}{3}\left(x^{2}+x+1\right)\right)+s x^{2}
$$

A legislator is indifferent between voting yes and no if and only if

$$
x^{2}-x\left(1-\frac{\delta}{6}\right)+\frac{\delta}{6}+3 x(1-x) s=0 .
$$


Because this equation is quadratic, there exist two equilibria in mixed strategies. Given the unique robust symmetric pure-strategy equilibrium described in Proposition 1, in period 1 the number of symmetric equilibria is therefore three.

Figure 1 shows these equilibria for different side payments $s$ and discount factors $\delta$. Given a side payment, say $s=0$, which indicates the right-most discontinuous curve, for any $\delta$ the two mixed-strategy equilibria have very different comparative statics. For the first equilibrium (the lower part of the discontinuous curve), an increase in the discount factor $\delta$ increases the probability that a legislator votes yes; in the second equilibrium (the upper part of the discontinuous curve) the opposite holds. ${ }^{33}$ As $\delta$ increases the mixed-strategy equilibria converge toward each other.

Interestingly, with more legislators and a discount factor smaller than 1, this convergence might be complete: mixed-strategy equilibria appear not to exist for high discount factors. When the future is important enough, the legislator strictly prefers to increase his chances of membership in the minimum winning coalition in period 2 rather than to reduce the probability that an exploitive policy is approved in period 1. For example, with five legislators and an agenda setter, for a mixed-strategy equilibrium to exist the discount factor must be smaller than 0.6. ${ }^{34}$

The right-most discontinuous curve in Figure 1 applies when $s=0$; curves further to the left are based on higher payments. The most the agenda setter is willing to pay to each legislator to induce the equilibrium in Proposition 1 is $t=\left(1-x^{3}-3 x^{2}(1-x)\right) / 3$, because $x^{3}+3 x^{2}(1-x)$ is his expected payoff in

\footnotetext{
${ }^{33}$ One could argue that the first equilibrium is more appealing than the second. First, it is plausible that as the future becomes more important the proposal in period 1 is more often approved. Second, as the discount factor approaches zero, the first equilibrium converges to the symmetric pure-strategy equilibrium in which the proposal is unanimously rejected. The second equilibrium converges to unanimous approval. For $\delta=0$, unanimous approval is only sustained in equilibrium because of a coordination failure. Third, for any discount factor the expected payoffs are strictly higher at the first equilibrium. Lastly, when there is a collective mistake in which everyone mixes with slightly different probability, the first equilibrium is stable, whereas the second equilibrium is unstable.

${ }^{34}$ With five legislators, a mixed strategy allows for trading off the increased chance of membership in the minimum winning coalition in period 2 , given by $\delta(1-x)^{4}(2 / 25)+\delta x(1-$ $x)^{3}(1 / 10)+\delta x^{2}(1-x)^{2}(2 / 15)+\delta x^{3}(1-x)(3 / 20)+\delta x^{4}(3 / 25)$, with the increased probability that an exploitive policy is approved in period $1, x^{2}(1-x)^{2} / 5$. The former is always larger than $\delta(1 / 2)^{4}(16 / 75)$, whereas the latter is at most $(1 / 2)^{4}(1 / 15)$. Equality can therefore not hold for large $\delta$.
} 
period 1 from the mixed-strategy equilibrium.

The figure shows that when the discount factor is sufficiently large (roughly greater than 0.6), the agenda setter can avoid a mixed-strategy equilibrium by making side payments. For low discount factors, however, the equilibrium in Proposition 1 cannot be induced. When the future is not sufficiently important, a legislator little values membership in the minimum winning coalition in period 2 , and strictly prefers to reduce the probability that an exploitive policy is approved in period 1. In these situations playing a mixed strategy can thus protect the legislature from complete exploitation - although it cannot eliminate the exploitation completely.

\section{A.2 Tacit collusion with a finitely repeated game}

Even with only three periods the legislature can avoid payments to the agenda setter in the first period, and reduce exploitation in the second. To do so it requests (in the first two periods) side payments, threatening to play the asymmetric equilibrium in the current period. Moreover, in the first period the legislature can increase side payments further to $1 / 3$ by threatening fellow legislators to punish the acceptance of less than $1 / 3$ by playing the unanimous approval equilibrium in the second period. As in the main text, if in period 2 punishment of fellow legislators requires approval, the agenda setter does not offer side payments. This increases the stakes in period 1 and makes it possible to require higher side payments in the earlier period.

Suppose there are three periods and the agenda setter plays the exclusion strategy as explained in the main text, but paying $s_{1}$ and $s_{2}$ in the first two periods. We show that the legislature can request to set

$$
\hat{s}_{1}=1 / 3, \quad \hat{s}_{2}=(2-\delta) / 6 .
$$

We say the second period is a punishment phase if some legislator vote yes in the first period although side payments were strictly smaller than $1 / 3$. In this case set $\hat{s}_{2}=0$ and notice that the agenda setter has no incentive to pay more than that; he modifies the exclusion strategy accordingly.

Consider the following strategies:

- Legislator 1 approves all proposals, except if the second period is a punishment phase. 
- Legislators 2 and 3 vote yes in the final period if and only if they belong to the minimum winning coalition. They vote yes on the first and second proposal if and only if $s \geq \hat{s}_{t}, t=1,2$.

We proceed by backward induction. Consider the final period. As before the proposal is approved by a minimum winning coalition.

Consider period 2. Suppose it is the punishment phase. A legislator who does not punish does not change policy but is less likely to belong to the minimum winning coalition in period 3; so all punish. The agenda setter cannot do better. Suppose it is not a punishment phase. Legislators 2 and 3 are pivotal and (following the analysis in Subsection 4.1) prefer to vote yes if and only if $s \geq \hat{s}_{2}$. Legislator 1 cannot change policy, and so cannot gain from voting against. The agenda setter cannot do better than setting $\hat{s}_{2}=(2-\delta) / 6$.

Consider period 1. Suppose $s_{1}=1 / 3$. A legislator who does not vote yes does not change policy but is less likely to belong to the minimum winning coalition in period 3; so all vote yes. Suppose $s_{1}<1 / 3$. Legislators 2 and 3 are pivotal. Voting yes ensures belonging to the winning coalition in period 3 , but implies that period 2 is a punishment phase, so the payoff is

$$
-\frac{1}{3}\left(1+\delta+\delta^{2}\right)+s_{1}+\frac{\delta^{2}}{3}
$$

Not deviating and voting against foregoes current side payments but assures side payments in period 2 yielding

$$
-\frac{1}{3}\left(\delta+\delta^{2}\right)+\delta \hat{s}_{2}+\frac{\delta^{2}}{6}=-\frac{1}{3}\left(\delta+\delta^{2}\right)+\delta(2-\delta) / 6+\frac{\delta^{2}}{6} .
$$

Voting against is beneficial because

$$
-\frac{1}{3}+s_{1}-\delta(2-\delta) / 6+\frac{\delta^{2}}{6}=s_{1}-\frac{1}{3}-\delta(1-\delta) / 3<0 .
$$

Legislator 1 cannot change policy, and so cannot gain from voting against. Thus the agenda setter cannot do better than offering $\hat{s}_{1}=1 / 3$.

Similar to the infinite horizon, the finite horizon can sustain very different behavior in equilibrium. Multiple periods can allow the agenda setter to exploit the legislature in more periods, and exploitation may appear for any finite number of periods.

Consider $T$ periods, denoted by $t=1, \ldots, T$. A value of $T=2$ gives the setting of Section 4. Again, the agenda setter modifies the exclusion strategy 
as stated in the main text, and a minimum winning coalition will approve the proposal the agenda setter makes in the final period.

Consider now a given legislator in any period $t$ before the final one, with all other legislators voting yes in that period. Because a single vote does not change the outcome of the collective decision which approves the proposal, by voting yes the legislator obtains

$$
-\frac{1-\delta^{T-t}}{3(1-\delta)}+\frac{2 \delta^{T-t-1}}{9},
$$

the discounted value of tax payments in all periods plus the option value of potential membership in the minimum winning coalition in period $T$. A legislator who votes no does not reduce his tax, but excludes himself from future benefits, yielding him expected benefits of

$$
-\frac{1-\delta^{T-t}}{3(1-\delta)}
$$

Because the difference is strictly positive, a legislator strictly prefers to vote yes in periods $t<T$. It follows that there is a subgame perfect equilibrium in symmetric pure strategies with each legislator voting yes in each period $t<T$, and in the final period a minimum winning coalition approves the agenda setter's proposal.

Thus even under a finite horizon legislators can reduce exploitation considerably. Again, other behavior is also possible, including the approval of exploitive proposals in every period but the final one. 


\section{References}

[1] Ali, N.S., Bernheim, B.D., Fan, X., 2014. Predictability and power in legislative bargaining. National Bureau of Economic Research Working Paper Series No. 20111.

[2] Anesi, V., Seidmann, D.J., 2013. Bargaining over an endogenous agenda. Theoretical Economics, forthcoming.

[3] Anesi, V., Seidmann, D.J., 2015. Bargaining in Standing Committees with an Endogenous Default. Review of Economic Studies, forthcoming.

[4] Balla, S.J., Lawrence, E.D., Maltzman, F., Sigelman, L., 2002. Partisanship, blame avoidance, and the distribution of legislative pork. American Journal of Political Science 46(3), 515-525.

[5] Banks, J.S., 2000. Buying supermajorities in finite legislatures. American Political Science Review 94(3), 677-681.

[6] Barber, J.D., 1996. Leadership strategies for legislative party cohesion. Journal of Politics 28(2), 347-367.

[7] Baron, D. P., 1989. A noncooperative theory of legislative coalitions. American Journal of Political Science 33(4), 1048-1084.

[8] Baron, D.P., Ferejohn, J.A., 1989. Bargaining in legislatures. American Political Science Review 83(4), 1181-1206.

[9] Bernheim, B.D., Rangel, A., Rayo, L., 2006. The power of the last word in legislative policy making. Econometrica 74(5), 1161-1190.

[10] Bernheim, B.D., Whinston, M.D., 1998. Incomplete contracts and strategic ambiguity. American Economic Review 88(4), 902-932.

[11] Brollo, F., Nannicini, T., 2012. Tying your enemy's hands in close races: The politics of federal transfers in Brazil. American Political Science Review 106, 742-761.

[12] Bueno de Mesquita, B.B., Morrow, J., Siverson, R., Smith, A., 2002. Political institutions, policy choice and the survival of leaders. British Journal of Political Science 32(4), 559-590. 
[13] Console-Battilana, S., Shepsle, K.A., 2009. Nominations for sale. Journal of Theoretical Politics 21(4), 413-449.

[14] Corchón, L., Dahm, M., 2010. Foundations for contest success functions. Economic Theory 43, 81-98.

[15] Corchón, L., Dahm, M., 2011. Welfare maximizing contest success functions when the planner cannot commit. Journal of Mathematical Economics 47, 309-317.

[16] Cotton, C., 2010. Dynamic legislative bargaining with endogenous agenda setting authority. Working paper, Department of Economics, University of Miami.

[17] Dal Bó, E., 2007. Bribing voters. American Journal of Political Science 51(4), 789-803.

[18] de Figueiredo, J.M., Silverman, B.S., 2006. Academic earmarks and the returns to lobbying. Journal of Law and Economics 49(2), 597-626.

[19] Diaz-Cayeros, A., Magaloni, B., Weingast, B.R., 2003. Tragic brilliance: Equilibrium hegemony and democratization in Mexico. Hoover Institution, Stanford University.

[20] Diermeier, D., Fong, P., 2011. Legislative bargaining with reconsideration. Quarterly Journal of Economics 126(2), 947-985.

[21] Dixit, A., 2009. Governance institutions and economic activity. American Economic Review 99(1), 5-24.

[22] Doran, M., 2010. The closed rule. Emory Law Journal 59(6), 1363-1454.

[23] Engstrom, E.J., Vanberg, G., 2010. Assessing the allocation of pork: Evidence from congressional earmarks. American Politics Research 38(6), 959-985.

[24] Epple, D., Riordan, M.H., 1987. Cooperation and punishment under repeated majority voting. Public Choice 55(1-2), 41-73.

[25] Felgenhauer, M., Grüner, H.P., 2008. Committees and special interests. Journal of Public Economic Theory 10(2), 219-243. 
[26] Ferejohn, J., 1974. Pork Barrel Politics: Rivers and Harbors Legislation, 1947-1968. Stanford: Stanford University Press.

[27] Finocchiaro, C.J., 2002. Majoritarianism, partisanship and the Cannon speakership: Committee assignments during the partisan era of the U.S. House. Paper presented at the annual meeting of the American Political Science Association.

[28] Gaines, B.J., Sala, B.R., 2000. A further look at universalism and partisanship in congressional roll-call voting. Political Analysis 8(4), 399.

[29] Glazer, A., McMillan. H., 1990. Optimal coalition size when making proposals is costly. Social Choice and Welfare 7(4), 369-380.

[30] Glazer, A., McMillan. H., 1992. Amend the old or address the new: Broadbased legislation when proposing policies is costly. Public Choice 74(1), 43-58.

[31] Grofman, B., 1984. The general irrelevance of the zero sum assumption in the legislative context. In M. Holler (ed.) Coalitions and Collective Action, Physica-Verlag, Würzburg, 99-112.

[32] Groseclose, T., Snyder, Jr, J.M., 1996. Buying supermajorities. American Political Science Review 90(2), 303-315.

[33] Hardin, C.M., 1958. Farm political power and the U. S. governmental crisis. Journal of Farm Economics 40(5), 1646-1659.

[34] Harrington, J.E., 1990. The power of the proposal maker in a model of endogenous agenda formation. Public Choice 64(1), 1-20.

[35] Hird, J.A., 1991. The political economy of pork: Project selection at the U.S. Army Corps of Engineers. American Political Science Review 85(2), 429-456.

[36] Huber, J.D., 1996. The vote of confidence in parliamentary democracies. American Political Science Review 90(2), 269-282.

[37] Kalandrakis, A., 2004. A three-player dynamic majoritarian bargaining game. Journal of Economic Theory 116(2), 294-322. 
[38] King, D.C., Zeckhauser, R.J., 2003. Congressional vote options. Legislative Studies Quarterly 28(3), 387-411.

[39] Knight, B., 2005. Estimating the value of proposal power. American Economic Review 95(5), 1639-1652.

[40] Krehbiel, K., Wiseman, A., 2001. Joseph G. Cannon: Majoritarian from Illinois. Legislative Studies Quarterly 26(3), 357-389.

[41] Larcinese, V., Rizzo, L., Testa, C., 2006. Allocating the U.S. federal budget to the states: The impact of the president. Journal of Politics 68(2), 447456.

[42] Lazarus, J., Steigerwalt, A., 2009. Different Houses: The distribution of earmarks in the U.S. House and Senate. Legislative Studies Quarterly $34(3), 347-372$.

[43] Margolis, H., 1984. Selfishness, Altruism, and Rationality. Chicago: University of Chicago Press.

[44] Niskanen, W., 1971. Bureaucracy and Representative Government. Chicago: Aldine-Atherton.

[45] Norman, P., 2002. Legislative bargaining and coalition formation. Journal of Economic Theory 102(2), 322-353.

[46] Padró i Miquel, G., 2007. The control of politicians in divided societies: The politics of fear. Review of Economic Studies 74(4), 1259-1274.

[47] Price, D.E., 2006. Reflections on congressional government at 120 and Congress at 216. PS: Political Science and Politics 39(2), 231-235.

[48] Primo, D.M., 2002. Rethinking political bargaining: Policymaking with a single proposer. Journal of Law, Economics, and Organization 18(2), 411427.

[49] Riker, W.H., 1962. The Theory of Political Coalitions. New Haven: Yale University Press.

[50] Romer, T., Rosenthal, H., 1978. Political resource allocation, controlled agendas and the status quo. Public Choice 33(4), 27-43. 
[51] Rozevitch, S., Weiss, A., 1993. Beneficiaries from federal transfers to municipalities: The case of Israel. Public Choice 76(4), 335-346.

[52] Shayo, M., Harel, A., 2012. Non-consequentialist voting. Journal of Economic Behavior \& Organization 81(1), 299-313.

[53] Shepsle K.A., Weingast, B.R., 1981. Political preference for the pork barrel: A generalization. American Journal of Political Science 25(1), 96-111.

[54] Solé-Ollé, A., Sorribas-Navarro, P., 2008. The effects of partisan alignment on the allocation of intergovernmental transfers: Differences-in-differences estimates for Spain. Journal of Public Economics 92(12), 2302-2319.

[55] Tamura, K., 2010. Testing the partisan bias in the Japanese fiscal equalization system. Presented at the GLOPE II International Symposium on the Political Economy of Institutions and Expectations, Waseda University, Tokyo.

[56] Tsai, T.-S., Yang, C.C., 2010. On majoritarian bargaining with incomplete information. International Economic Review 51(4), 959-979.

[57] Tsebelis, G., Garret, G., 1996. Agenda setting power, power indices, and decision making in the European Union. International Review of Law and Economics 16, 345-361.

[58] Tullock, G., 1972. The purchase of politicians. Western Economic Journal $10,354-55$.

[59] Weingast, B.R., 1979. A rational choice perspective on congressional norms. American Journal of Political Science 23(2), 245-262.

[60] Zapal, J., 2013. Crafting consensus. Working Paper, IAE-CSIC, Barcelona GSE. 


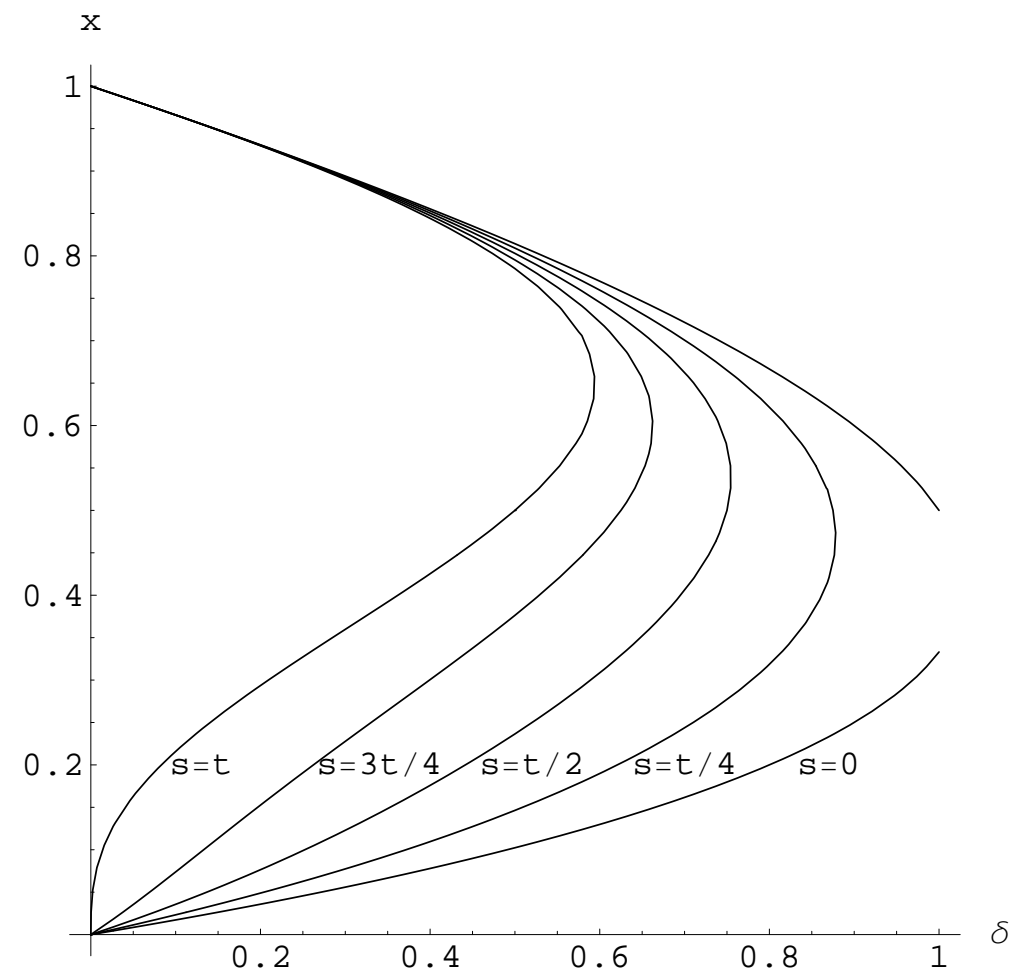

Figure 1: Mixed-strategy equilibria for different values of $\delta$ and $s$. 